\title{
Load-Sharing Characteristics of Power-Split Transmission System Based on Deformation Compatibility and Loaded Tooth Contact Analysis
}

\author{
Hao Dong, ${ }^{1}$ Ling-ling Duan, ${ }^{2}$ Jun-an Zhang, ${ }^{1}$ and Zhou Fang ${ }^{1}$ \\ ${ }^{1}$ School of Mechanical and Electronic Engineering, Xian Technological University, Xian 710021, China \\ ${ }^{2}$ Shaanxi Hualu Chemical Green Environmental Protection Co., Ltd., Xian 710025, China \\ Correspondence should be addressed to Hao Dong; donghaofane@sina.com
}

Received 20 July 2014; Revised 16 March 2015; Accepted 17 March 2015

Academic Editor: Shaoping Wang

Copyright (C) 2015 Hao Dong et al. This is an open access article distributed under the Creative Commons Attribution License, which permits unrestricted use, distribution, and reproduction in any medium, provided the original work is properly cited.

In order to implement the uniform load distribution of the power-split transmission system, a pseudostatic model is built. Based on the loaded tooth contact analysis (LTCA) technique, the actual meshing process of each gear pair is simulated and the fitting curve of time-varying mesh stiffness is obtained. And then, the torsional angle deformation compatibility conditions are proposed according to the closed-loop characteristic of power flow, which will be combined with the torque equilibrium conditions and elastic support conditions to calculate the transfer torque of each gear pair. Finally, the load-sharing coefficient of the power-split transmission system is obtained, and the influences of the installation errors are analyzed. The results show that the above-mentioned installation errors comprehensively influence the load-sharing characteristics, and the reduction of only one error could not effectively achieve perfect load-sharing characteristics. Allowing for the spline clearance floating and constrained by the radial spacing ring, the influence of the floating pinion is analyzed. It shows that the floating pinion can improve the load-sharing characteristics. Through the comparison between the theoretical and related experimental data, the reasonability and feasibility of the above-proposed method and model are verified.

\section{Introduction}

The power branching load-sharing technique is adopted in the power-split transmission system, which greatly meets the demand of high speed and overload, even in the condition of small dimensions and light weight. It makes two channels evenly share the total torque. This transmission system is predicted to have a broad application prospect in aerospace, industrial, and transportation fields. Improvement of load distribution is one of the main goals of design of power-split transmission system.

Many researchers had already analyzed the power branching load-sharing technique at home and abroad. Tsai et al. [1] have proposed an analytical approach for loadsharing analysis among the planet gears of a planetary gear set without floating mechanism and have further analyzed the influences of the errors on load sharing. Singh et al. [2] have presented the results of a comprehensive experimental and theoretical study to determine the influence of certain key factors in planetary transmissions on gear stresses and planetary load sharing. Li [3] has investigated the effects of machining errors, assembly errors, and tooth modifications on loading capacity, load-sharing ratio, and transmission error of a pair of spur gears by using specially developed finite element method software. A companion study to develop a method to analyze and optimize the load sharing of powersplit gearboxes has also been completed, and the results of that study were reported separately by Krantz [4, 5], and the effect of time-varying mesh stiffness had also been considered. Singh [6] has provided a physical explanation for the basic mechanism causing the unequal load-sharing phenomenon; both floating (system with clearances) and nonfloating systems were treated. White [7] has proposed a power-split design for helicopters and its use after concluding that such designs offer many advantages over the traditional planetary design, such as a high speed reduction ration at the final stage, lower energy losses, and increased reliability owing to separate drive paths. Ligata et al. [8] have presented 
a simplified discrete model to predict load sharing among the planets of a planetary gear set with planet carrier position errors and proposed a translational representation (expression) of the torsional system that includes any number of planets positioned at any spacing configuration. Bodas and Kahraman [9] have mainly considered the effect of manufacturing errors on the static load-sharing behavior of planetary gear sets and proposed three parameters of the load-sharing coefficient and static load-sharing coefficient describing the load-sharing behavior of the planetary gear trains. Sun [10] described power-split designs that feature quill shafts to minimize the torque loading differences between the two parallel power paths. Abousleiman and Velex [11] have presented a model which enables the simulation of the threedimensional dynamic behaviour of planetary/epicyclic spur and helical gears. Dynamic load-sharing behavior and loadsharing coefficient of star gear trains with effect of each levels connection stiffness and star gear eccentric errors have been analyzed by Fang et al. [12]. Both floating (system with clearances) and nonfloating systems have been considered for the unequal load-sharing phenomenon in cylindrical gears in work [13]. Du et al. [14] have found the torque balance equations of the $2 \mathrm{~K}$-H-type planetary transmission system based on the characteristic that the system comprised a closed-loop of power flow, and the effects of the errors on load sharing were studied. Dong et al. [15] have analyzed the load-sharing characteristics of dual power-split transmission system based on the deformation compatibility.

However, less recent research on power-split transmission system has considered the influence of gear surface tooth contact. In this paper, the actual meshing process of each gear pair will be dispersed into some limited meshing points, according to the method of theoretical analysis of loaded tooth contact analysis (LTCA). Statics characteristic of each meshing position is analyzed, and the mechanical properties are obtained. This approach will improve the accuracy of the calculation for system.

And much of recent researches only have considered the mechanical balance relationship among different components, and much of these recent researches have ignored the conditions for deformation compatibility formed by closedloop characteristics of system power flow. The errors of component will be superposed or counteract each other, through using the deformation compatibility conditions. The deformation compatibility conditions will more essentially reflect the mechanical property, especially for the power-split system with the closed-loop features.

The approach and contents of this paper are based on the following ideas:

(1) The mechanical structure and model of power-split transmission system are established.

(2) The torsional angle deformation compatibility conditions are proposed, according to the closed-loop characteristic of system power flow, and first applied to analyze the load sharing of power-split transmission system.

(3) The analysis is computerized by application of developed LTCA computer program. The time-varying

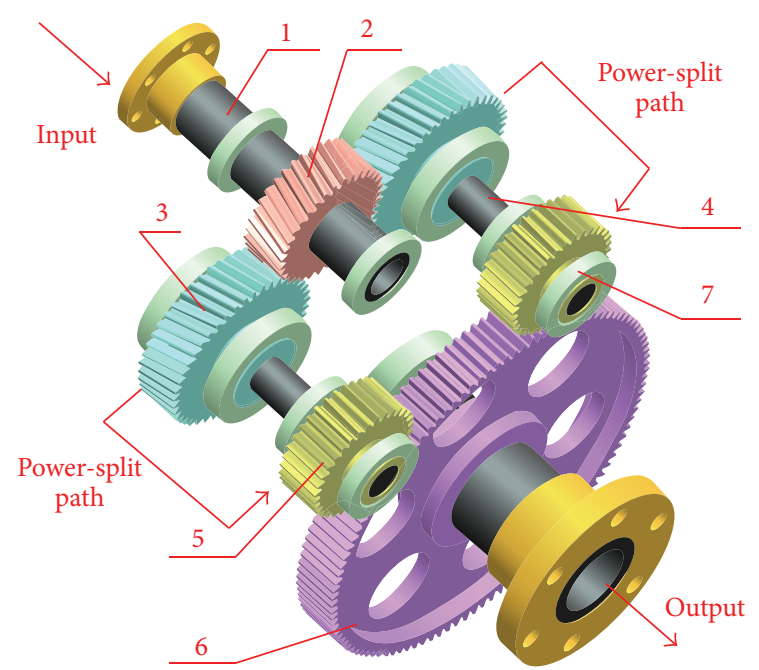

FIGURE 1: Example of a power-split transmission design with dual power paths. 1: input shaft, 2: I-stage helical pinion, 3: I-stage helical gear, 4: torsion shaft, 5: II-stage spur pinion, 6: II-stage spur gear, and 7: II-stage spur pinion.

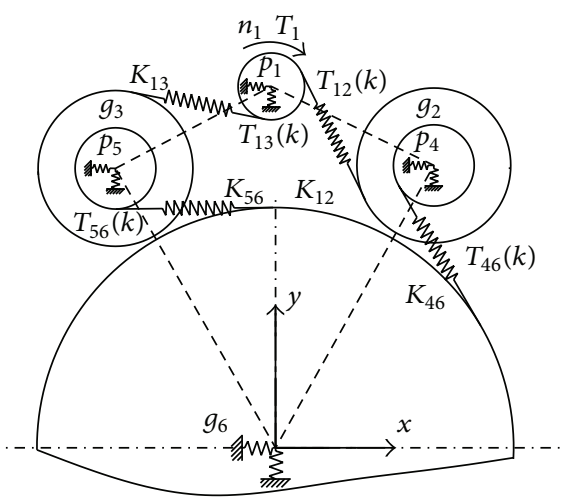

Figure 2: Schematic of mechanical structure model.

mesh stiffness of each gear pair will be formulated by this method.

(4) The case of a floating pinion based on the spline clearance floating and constrained by the radial spacing ring will be analyzed for the load sharing of system.

(5) It will give a contrast of numerical analysis data and experimental data related [4] to proving the validity of the method mentioned in this paper.

\section{Statics Mechanical Model}

The structure of split-path transmission system is shown in Figure 1. The I-stage helical pinion meshes with two gears and then transmits the power to the output II-stage spur gear. The key to the problem for the power-split transmission system now is how to solve the power equally distribute between the two loaded split paths.

The mechanical structure model is shown in Figure 2. 


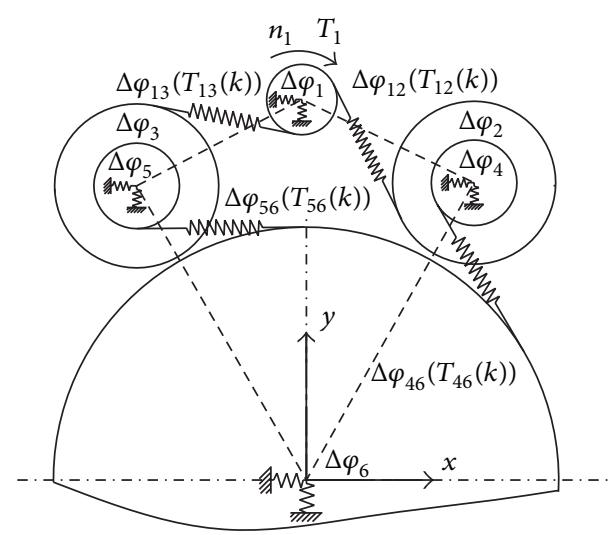

FIGURE 3: Torsional angle relationships among each gear.

Here, $T_{1}$ is input torque; $n_{1}$ is input speed; $K_{i j}(i=1, j=$ 2,$3 ; i=4,5, j=6$ ) is time-varying mesh stiffness; and transmitting torque of each gear pair is expressed as $T_{i j}=$ $-I_{i j} T_{j i}\left(I_{i j}\right.$ is the transmission ratio; $\left.I_{i j}=r_{b j} / r_{b i}=Z_{j} / Z_{i}\right)$. $r_{b i}$ and $r_{b j}$ stand for the basic radius, and $Z_{i}$ and $Z_{j}$ represent the teeth number, respectively, for the gear $j$ and pinion $i$; $p_{u}$ and $g_{v}(u=1, j=2,3 ; v=4,5, j=6)$ are the symbol of gears.

The torque equilibrium conditions are represented as

$$
\begin{gathered}
T_{1}-T_{12}(k)-T_{13}(k)=0 \\
T_{46}(k)-T_{12}(k) I_{12}=0 \\
T_{56}(k)-T_{13}(k) I_{13}=0 .
\end{gathered}
$$

Here, $T_{i j}(k)(k=1,2, \ldots, 5)$ represents the torque of the $k$ th meshing position of the gear $j$ relative to the pinion $i$ in a meshing cycle.

\section{Deformation Compatibility Conditions}

The meshing torsional angles among gear pairs are defined as [16]

$$
\Delta \varphi_{i j}\left(T_{i j}(k)\right)=\Delta \varphi_{i}-I_{i j} \Delta \varphi_{j}
$$

where $\Delta \varphi_{i}$ and $\Delta \varphi_{j}$ are, respectively, the torsional angle of pinion $i$ and gear $j ; \Delta \varphi_{i j}\left(T_{i j}(k)\right)$ is the deformation of torsional angle of the pinion $i$ relative to the gear $j$ under the torque $T_{i j}(k)$.

The torsional angle relationships among gear pairs under torque $T_{i j}(k)$ are shown in Figure 3.

According to the closed-loop characteristics of system power flow, the power will be offered to two parallel paths. One path is comprised of pinion 1 , gear 2 , torsion shaft, pinion 4 , and gear 6 , while another path consists of pinion 1 , gear 3 , torsion shaft, pinion 5, and gear 6 .
Here, a torsion angle deformation will be produced to the compound shaft, which can be expressed as $\Delta \varphi_{24}\left(T_{24}\right)=$ $\Delta \varphi_{2}-\Delta \varphi_{4}$ and $\Delta \varphi_{35}\left(T_{35}\right)=\Delta \varphi_{3}-\Delta \varphi_{5}$. The following equation can be obtained:

$$
\begin{aligned}
& \Delta \varphi_{12}\left(T_{12}(k)\right)+I_{12} \Delta \varphi_{24}\left(T_{24}(k)\right)+I_{12} \Delta \varphi_{46}\left(T_{46}(k)\right) \\
& =\Delta \varphi_{1}-I_{12} I_{46} \Delta \varphi_{6}, \\
& \Delta \varphi_{13}\left(T_{13}(k)\right)+I_{13} \Delta \varphi_{35}\left(T_{35}(k)\right)+I_{13} \Delta \varphi_{56}\left(T_{56}(k)\right) \\
& =\Delta \varphi_{1}-I_{13} I_{56} \Delta \varphi_{6},
\end{aligned}
$$

where, due to $I_{12}=I_{13}$ and $I_{46}=I_{56}$, from the above mentioned, the deformation compatibility conditions are established and described as

$$
\begin{aligned}
\Delta \varphi_{12} & \left(T_{12}(k)\right)+I_{12} \Delta \varphi_{24}\left(T_{24}(k)\right)+I_{12} \Delta \varphi_{46}\left(T_{46}(k)\right) \\
= & \Delta \varphi_{13}\left(T_{13}(k)\right)+I_{13} \Delta \varphi_{35}\left(T_{35}(k)\right) \\
& +I_{13} \Delta \varphi_{56}\left(T_{56}(k)\right),
\end{aligned}
$$

where $\Delta \varphi_{24}\left(T_{24}(k)\right)$ and $\Delta \varphi_{35}\left(T_{35}(k)\right)$ are torsional angle of torsion shaft under torque $T_{i j}(k)$ and represented as

$$
\begin{gathered}
\Delta \varphi_{24}\left(T_{24}(k)\right)=\Delta \varphi_{2}-\Delta \varphi_{4}=\frac{T_{24}(k)}{N_{24}}, \\
\Delta \varphi_{35}\left(T_{35}(k)\right)=\Delta \varphi_{3}-\Delta \varphi_{5}=\frac{T_{35}(k)}{N_{35}},
\end{gathered}
$$

where $N_{24}$ and $N_{35}$ are the torsional rigidity.

The displacement $\Delta L_{i j}$ of installation errors projected on the meshing line of action is represented as

$$
\begin{aligned}
\Delta L_{i j}= & {\left[\left(x_{i}+\Delta A_{x i}\right)-\left(x_{j}+\Delta A_{x j}\right)\right] \cos \chi_{i j} } \\
& +\left[\left(y_{i}+\Delta A_{y i}\right)-\left(y_{j}+\Delta A_{y j}\right)\right] \sin \chi_{i j},
\end{aligned}
$$

where $x_{i}$ and $x_{j}$ are displacement deformations along the $x$ axis, $y_{i}$ and $y_{j}$ are displacement deformations along the $y$ axis, $\Delta A_{x i}$ and $\Delta A_{x j}$ are the amplitude of errors along the $x$ axis, and $\Delta A_{y i}$ and $\Delta A_{y j}$ are the amplitude of errors along the $y$-axis, respectively, for the pinion $i$ and gear $j . \chi_{i j}$ is the actual operating pressure positive angle of the line of action down from $x$-axis.

The meshing forces of each gear pair are represented as

$$
\frac{T_{i j}(k)}{r_{b i}}=K_{i j}\left(r_{b i} \Delta \varphi_{i}-r_{b j} \Delta \varphi_{j}+\Delta L_{i j}\right) .
$$

The meshing torsional angle $\Delta \varphi_{i j}\left(T_{i j}(k)\right)$ of each gear pair may be transformed into

$$
\Delta \varphi_{i j}\left(T_{i j}(k)\right)=\frac{\left(T_{i j}(k) / r_{b i} / K_{i j}-\Delta L_{i j}\right)}{r_{b i}} .
$$

And the elastic support conditions are represented as

$$
\begin{aligned}
& \sum\left(\frac{T_{i j}(k)}{r_{b i}} \cdot \cos \chi_{i j}\right)-K_{x i} x_{i}=0, \\
& \sum\left(\frac{T_{i j}(k)}{r_{b i}} \cdot \sin \chi_{i j}\right)-K_{y i} y_{i}=0,
\end{aligned}
$$




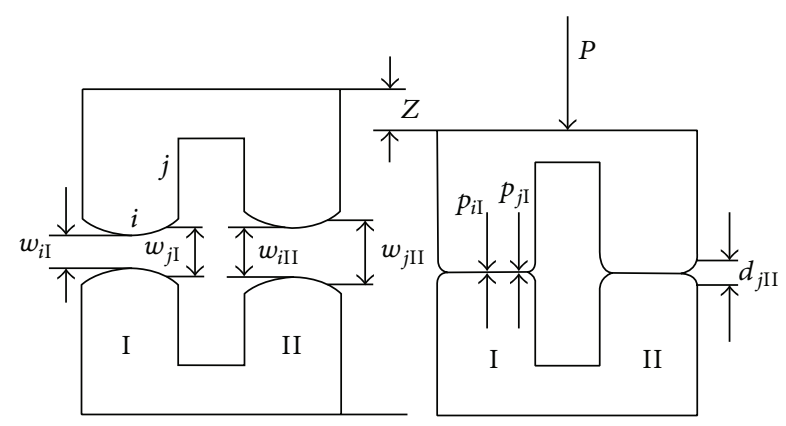

FIGURE 4: Model for loaded tooth contact analysis.

where $K_{x i}$ and $K_{y i}$ are the equivalent supporting rigidity of gear $i(i=1,2, \ldots, 6)$ along the $x$-axis and $y$-axis, respectively.

The deformation compatibility conditions will be obtained through substituting (8) into (4). And then, the deformation compatibility conditions will be combined with the torque equilibrium conditions (1) and elastic support conditions (9) to establish bending-torsional coupling relationship. Finally, the transmission torque $\bar{T}_{i j}$ of each gear pair will be solved.

The load-sharing coefficient can be described as

$$
\left[J_{46} J_{56}\right]^{\mathrm{T}}=\frac{\left[\bar{T}_{46} \bar{T}_{56}\right]^{\mathrm{T}}}{\left[\left(T_{1} / 2\right) I_{12}\right]} .
$$

Ultimately, the load-sharing coefficient can be represented as $J=\left\{\left[J_{46} J_{56}\right]^{\mathrm{T}}\right\}_{\text {MAX }}$.

The smaller the value of load-sharing coefficient is, the smaller the difference of load distribution on each gear pair is and the better the load-sharing characteristics are, and vice versa. The load-sharing coefficient is also an important calculation basis for vibration analysis of power-split transmission.

\section{Time-Varying Mesh Stiffness Based on Loaded Tooth Contact Analysis}

When a particular external load is exerted on it, the gear teeth will produce a deformation of torsional angle. The geometry transmission errors can be represented as $\delta_{1}(T(k))=a$; the tooth bending deformations can be represented as $\delta_{2}[T(k)]=$ $b T(k)$; and tooth contact deformations can be represented as $\delta_{3}[T(k)]=c T(k)^{2 / 3}$. Functional relation between $\Delta \varphi_{i j}\left(T_{i j}(k)\right)$ and $T_{i j}(k)$ is expressed as follows $[17,18]$. Here, $a, b$, and $c$ are constant:

$$
\begin{aligned}
\Delta \varphi_{i j}\left(T_{i j}(k)\right) & =\delta_{1}(T(k))+\delta_{2}[T(k)]+\delta_{3}[T(k)] \\
& =a+b T_{i j}(k)+c T_{i j}(k)^{2 / 3}
\end{aligned}
$$

LTCA model is shown in Figure 4, where the two pairs of teeth which contacted each other at a specific moment in the meshing cycle are denoted by I and II [19-22].

As shown in Figure 4, the tooth surface curve is vertical along the relative principal direction in the normal plane.
$i_{k}(k=\mathrm{I}, \mathrm{II})$ is the contact point and $j_{k}$ is a point along the relative principal direction.

Under the load $P$, the state of contact of the tooth pair $k$ can be described as

$$
\begin{gathered}
{[F]_{k}\left[p_{j}\right]_{k}+[w]_{k}=[Z]+\left[d_{j}\right]_{k} \quad(k=\mathrm{I}, \mathrm{II})} \\
\text { if }\left[p_{j}\right]_{k}>0, \text { then }\left[d_{j}\right]_{k}=0, \\
\sum_{j=1}^{n} p_{j \mathrm{I}}+\sum_{j=1}^{n} p_{j \mathrm{II}}=P \text { if }\left[p_{j}\right]_{k}=0, \text { then }\left[d_{j}\right]_{k}>0,
\end{gathered}
$$

where $\left[p_{j}\right]_{k}=\left[p_{1}, p_{2}, \ldots, p_{n k}\right]^{\mathrm{T}},\left[d_{j}\right]_{k}=\left[d_{1}, d_{2}, \ldots, d_{n k}\right]^{\mathrm{T}}$, and $[Z]=[Z]_{k}[1,1, \ldots, 1]^{\mathrm{T}} ;[F]_{k}$ is the flexibility matrix; $p_{j}$ $\left(j=1,2, \ldots, n_{k}\right)$ is the contact load supported at point $j$ of the tooth pair $k ; d_{j}\left(j=1,2, \ldots, n_{k}\right)$ is the final tooth clearance at point $j$; and $Z_{k}$ is the tooth approach that is the same for the whole tooth at a particular contact position during a meshing cycle.

The known parameters $(f, P, w)$ and the unknowns parameters $(p, d, Z)$ constitute a nonlinear program model. According to the tooth approach $Z_{k}$, we may establish the following objective function:

$$
\text { Minimize }[p]^{\mathrm{T}}\{[F][p]+[w]-[Z]\} \text {. }
$$

Equations (12) and (13) represent a constrained nonlinear programming problem, which is solved by the modified simplex method.

The objective function (13) forms a nonlinear programming model with functions (11) and (12) as constraint conditions:

$$
\begin{array}{ll}
\text { Min } & \sum_{j=1}^{2 n+1} X_{j}-[F][p]+[Z]+[d]+[X]=[w] \\
\text { S.t. } & {[e]^{\mathrm{T}}[p]+X_{2 n+1}=P} \\
& p_{j} \geq 0, d_{j} \geq 0, Z \geq 0, X_{j} \geq 0 ; p_{j}=0 \text { or } d_{j}=0,
\end{array}
$$

where $X_{j}(j=1,2, \ldots, 2 n+1)$ is the artificial variables; $[e]$ of each element is equal to 1 .

The tooth approach $Z$ is the linear displacement error $\Delta \delta_{i j}\left(T_{i j}(k)\right)$. The corresponding angular transmission error $\Delta \varphi_{i j}\left(T_{i j}(k)\right)$ is determined by

$$
\Delta \varphi_{i j}\left(T_{i j}(k)\right)=\frac{\Delta \delta_{i j}\left(T_{i j}(k)\right)}{r_{b i}} \cdot \cos \xi_{i} .
$$

Here, $\xi_{i}$ is the helix angle.

The load distribution on the contact lines of the tooth surface is shown in Figure 5. The parameters of system are related to Table 1 in Section 7.

The loaded transmission error (LTE) of each gear pair of the system related to Table 1 is shown in Figure 6.

Finally, the whole system LTCA model is established and shown in Figure 7. We can obtain loaded transmission errors 
TABLE 1: Gear parameters.

\begin{tabular}{lccccc}
\hline Gear & Teeth $z$ & $\begin{array}{c}\text { Pitch diameter } \\
d /(\mathrm{mm})\end{array}$ & $\begin{array}{c}\text { Tooth width } \\
b /(\mathrm{mm})\end{array}$ & $\begin{array}{c}\text { Pressure angle } \\
\alpha /\left(^{\circ}\right)\end{array}$ & $\begin{array}{c}\text { Helical angle } \\
\beta /\left(^{\circ}\right)\end{array}$ \\
\hline $\mathbf{1}$ & 32 & 51.1 & 44.5 & 20 & $\mathbf{6}$ \\
$\mathbf{2}, \mathbf{3}$ & 124 & 197.9 & 38.1 & 20 & $\mathbf{6}$ \\
$\mathbf{4 , 5}$ & 27 & 68.6 & 66 & 20 & $\mathbf{0}$ \\
\hline $\mathbf{6}$ & $\mathbf{1 7 6}$ & $\mathbf{4 4 7 . 0}$ & $\mathbf{5 9 . 9}$ & $\mathbf{2 0}$ & $\mathbf{0}$ \\
\hline
\end{tabular}

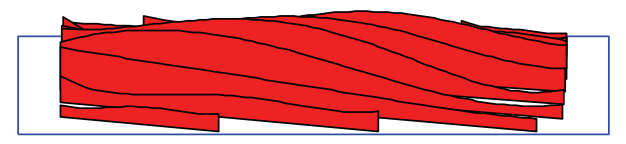

(a)

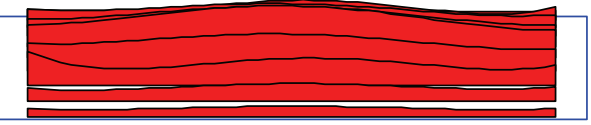

(b)

FIGURE 5: Load distribution on the tooth surface. (a) I-stage helical gear pairs. (b) II-stage spur gear pairs.

Initial torsional angle of the active pinion $1 \varphi_{1} /\left(2 \pi / z_{1}\right)\left(^{\circ}\right)$

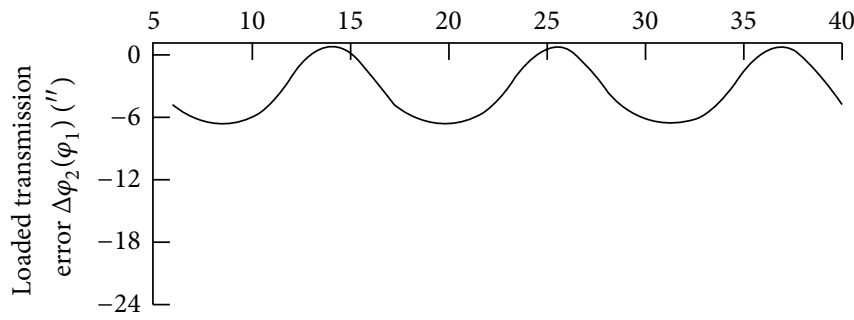

(a) I-stage helical gear pairs
Initial torsional angle of the active pinion $i \varphi_{i} /\left(2 \pi / z_{i}\right)(i=4,5)\left(^{\circ}\right)$

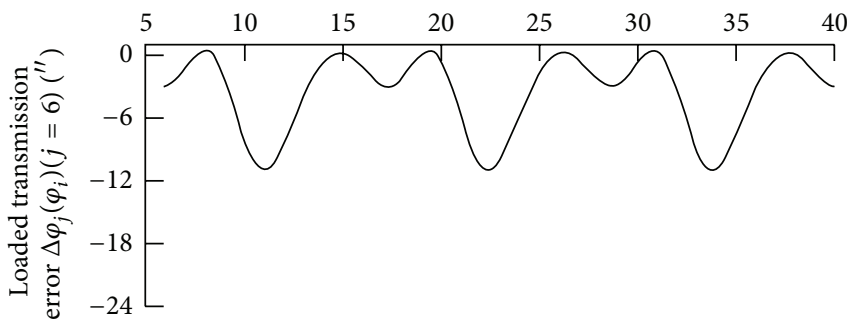

(b) II-stage spur gear pairs

FIguRE 6: Transmission errors.

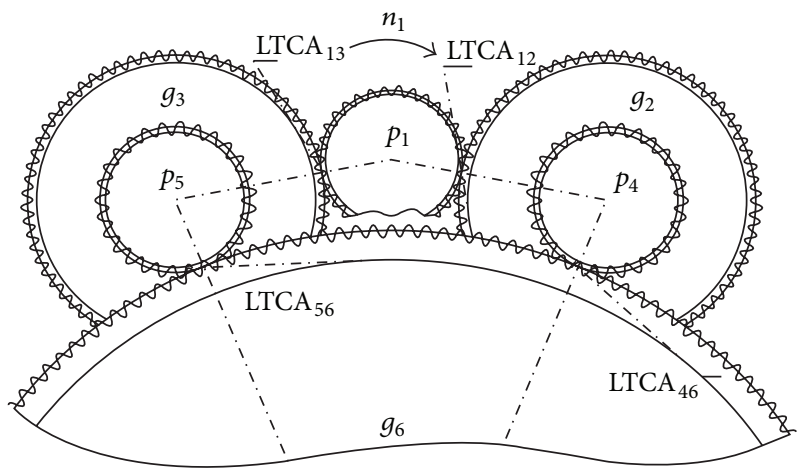

FIgure 7: The whole system LTCA model.

under different torques at meshing position $k$ of each gear pair through LTCA method (Figure 8).

For example, the loaded transmission error (LTE) of gear pair 12 is shown in Figure 11, when the pinion shafts under the torques of $0,0.1 T_{12}, 0.5 T_{12}, 0.9 T_{12}$, and $T_{12}$. Here, $T_{12}=$ $1.29 \times 10^{5} \mathrm{~N} \cdot \mathrm{mm}$.

And then, the loaded transmission errors are, respectively, substituted into (11); we can establish the following equation to obtain the coefficient of $a, b$, and $c$ :

$$
\begin{aligned}
& a+b \cdot 0.1 T_{i j}(k)+c \cdot 0.1 T_{i j}(k)^{2 / 3}=\left(\Delta \varphi_{i j}\left(0.1 T_{i j}(k)\right)\right), \\
& a+b \cdot 0.5 T_{i j}(k)+c \cdot 0.5 T_{i j}(k)^{2 / 3}=\left(\Delta \varphi_{i j}\left(0.5 T_{i j}(k)\right)\right),
\end{aligned}
$$

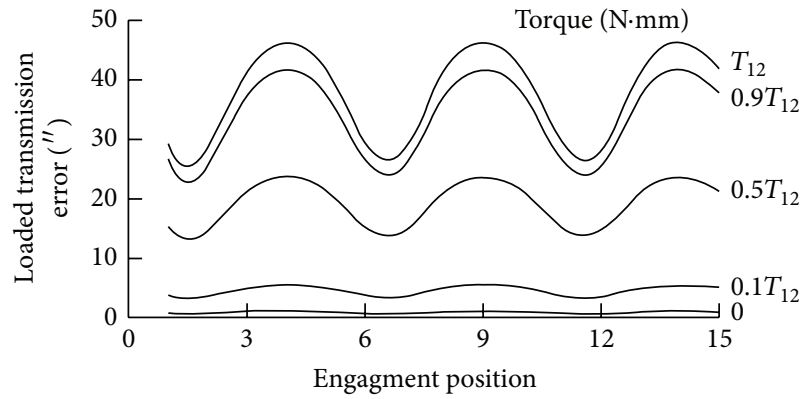

FIGURE 8: Loaded transmission errors under different load.

$$
\begin{array}{r}
a+b \cdot 0.9 T_{i j}(k)+c \cdot 0.9 T_{i j}(k)^{2 / 3}=\left(\Delta \varphi_{i j}\left(0.9 T_{i j}(k)\right)\right), \\
(i=1, j=2,3 ; i=4,5, j=6) .
\end{array}
$$

Then, functional relations between loaded transmission errors and $T_{i j}(k)$ are proposed.

The tooth approach $Z$ solved from the nonlinear programming problem for each contact position is actually the loaded tooth transmission errors as the amount of linear displacement error $\left(\Delta \delta_{i j}\right)$ of the driven gear along the contact normal (the line of action). The corresponding angular transmission error $\left(\Delta \varphi_{i j}\left(T_{i j}(k)\right)\right)$ under load for the contact position is determined by reversing (16). The column vector 


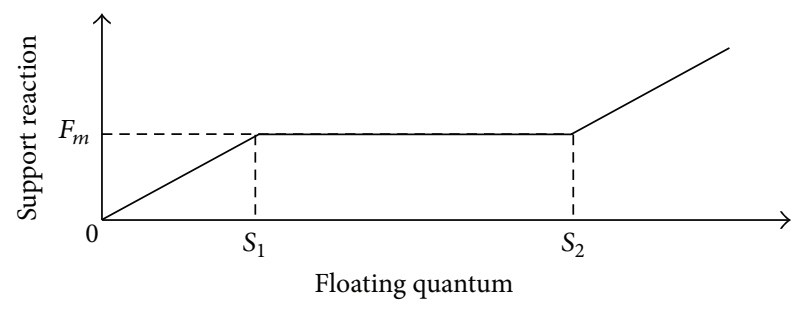

FIGURE 9: Supporting rigidity for floating pinion.

$[p]$ is solved from the programming problem representing the discrete distribution of the contact load along the contact line that coincides with the relative principal direction.

By solving (5), we can obtain the coefficient of $a, b$, and $c$. Then, functional relations between loaded transmission errors and some nominal load of $T_{i j}(k)$ may be proposed. The calculation curves are supplied in a meshing cycle. The timevarying mesh stiffness is represented by

$$
K_{i j}(k)=\frac{T_{i j}(k)}{r_{i} \cos \alpha_{n}} \cdot \frac{1}{r_{b i} \Delta \varphi_{i j}\left(T_{i j}(k)\right)} .
$$

Here, $r_{i}$ is the pitch radius and $\alpha_{n}$ is the pressure angle. The gear pairs are meshed with each other at different meshing positions; accordingly, the number of tooth pairs will have a change. The mesh stiffness could reflect real meshing elastic properties at the meshing position more directly. The discrete value of meshing stiffness is fitted by the polynomial and through the Fourier series transformation to spread out into a periodic function.

\section{Spline Clearance Floating}

In order to improve the uniform load distribution of the power-split transmission system and solve the problem that elastic torsion shaft cannot completely satisfy the demand of the load-sharing characteristics, a structure with I-stage pinion floating is proposed.

The I-stage floating pinion is installed on one end of input shaft with high speed and connected with output components through a short spline. The spline can transmit the torque. However, floating pinion cannot completely float freely under the constraint of spline coupling. The supporting rigidity of floating pinion can be described in Figure 9.

When the spline transmits torque, friction will be produced between internal and external spline and represented as $F_{m}=\tau F_{m}$; here, $F_{m}$ is the positive pressure between internal and external spline and $\tau$ is friction coefficient. The floating quantum can be represented as

$$
R=\sqrt{\left(x_{1}^{(n) 2}+y_{1}^{(n) 2}\right)}
$$

where $x_{1}^{(n)}$ and $y_{1}^{(n)}$ are the floating quantum along the $x$ direction and $y$-direction, respectively; $n$ is the iterations.

The floating pinion is affected by both of the engaging force of the two associated gears and support reaction of spline coupling. When the support reaction is less than the friction, the internal and external spline cannot produce a slippage. Here, the bending deflection of input shaft will adapt to the change of position of floating pinion, which is shown in Figure 9 from 0 to $S_{1}$. When the support reaction is greater than the friction, the internal and external spline will produce a slippage. Here, the slippage will adapt to the change of positions of floating pinion, which is from $S_{1}$ to $S_{2}$. However, if the slippage is beyond $S_{2}$-namely, radial clearance between internal and external spline is eliminatedthe bending deflection of input shaft will again adapt to the change of position of floating pinion. $S_{1}-S_{2}$ represents the radial clearance between the internal and external spline. $\Delta F_{x 1}^{(n)}$ and $\Delta F_{y 1}^{(n)}$ represent the support reaction of floating pinion projected on the $x$-axis and $y$-axis, respectively:

$$
\begin{aligned}
& \Delta F_{x 1}^{(n)}= \begin{cases}-K_{w} \cdot R \cdot \cos \left(\zeta^{(n)}\right) & 0 \leq R \leq S_{1} \\
-F_{m} \cdot \cos \left(\zeta^{(n)}\right) & S_{1}<R \leq S_{2} \\
-\left[F_{m}+K_{w} \cdot\left(R-S_{2}\right)\right] \cdot \cos \left(\zeta^{(n)}\right) & R>S_{2},\end{cases} \\
& \Delta F_{y 1}^{(n)}= \begin{cases}-K_{w} \cdot R \cdot \sin \left(\zeta^{(n)}\right) & 0 \leq R \leq S_{1} \\
-F_{m} \cdot \sin \left(\zeta^{(n)}\right) & S_{1}<R \leq S_{2} \\
-\left[F_{m}+K_{w} \cdot\left(R-S_{2}\right)\right] \cdot \sin \left(\zeta^{(n)}\right) & R>S_{2},\end{cases}
\end{aligned}
$$

where $K_{w}$ is the flexural rigidity of spline shaft and $\zeta^{(n)}$ is a direction angle of vector of $\left(x_{1}{ }^{(n)}, y_{1}{ }^{(n)}\right)$.

The support equilibrium conditions of the floating pinion can be represented as

$$
\begin{array}{r}
\sum\left(\frac{T_{i j}}{r_{b i}} \cdot \cos \chi_{i j}\right)+\Delta F_{x 1}^{(n)}=0, \\
\sum\left(\frac{T_{i j}}{r_{b i}} \cdot \sin \chi_{i j}\right)+\Delta F_{y 1}^{(n)}=0, \\
(i=1, j=2,3) .
\end{array}
$$

Equations (21) will be combined with the torque equilibrium conditions, elastic support conditions, and deformation compatibility conditions to establish clearance nonlinear mathematical model, and then through solving this nonlinear mathematical model, the transmission torque of each gear pair is obtained; finally the load-sharing coefficient of system will be obtained.

\section{Radial Limit Conditions Based on the Radial Spacing Ring}

A limiting device is added between the floating pinion and the two associated gears to limit the excessive radial floating displacement of the floating pinion and ensure that the floating pinion can meet the normal engagement. The structure of the radial spacing ring is shown in Figure 10.

The radial spacing rings are, respectively, added on both ends of floating pinion and play a supplementary role in uniform load distribution. Among three radial spacing 


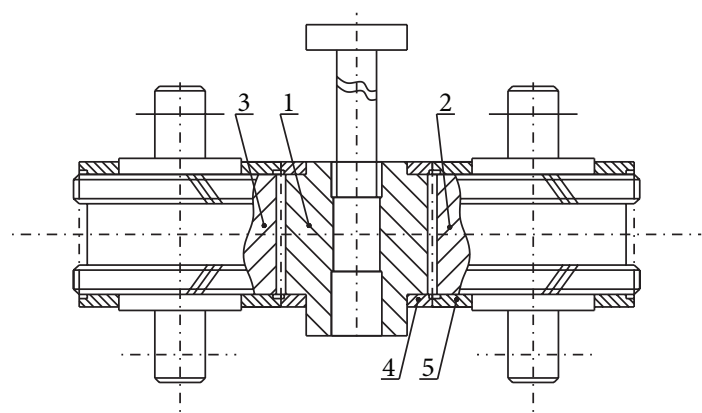

FIGURE 10: Structure of the spacing ring. 1: floating pinion, 2: gear, 3: gear, 4: radial spacing ring installed in floating pinion, and 5: radial spacing ring installed in gears.

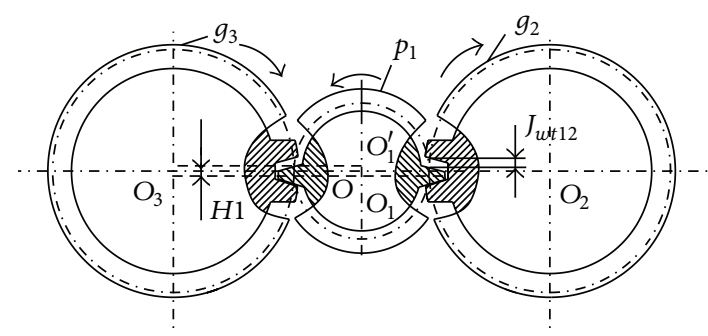

FIgURE 11: Closed movement relationship.

rings have rolling motion and without slipping. The outside diameters of radial spacing rings, respectively, installed in floating pinion and two gears are equal to the pitch diameter of floating pinion and two gears. The radial spacing ring only allows the floating pinion to produce a displacement along $y$ direction. It should be guaranteed that the floating pinion has a synchronous movement with two associated gears, which is shown in Figure 11.

Due to the radial limit of the radial spacing ring, the floating pinion cannot freely float. When the floating pinion meshes with gear 3 , it is due to the effect of meshing forces that the center of floating pinion has a trend to move up to eliminate circumferential backlash $j_{w t 12}$ between floating pinion and gear 2; here, the center $O$ of floating pinion is floated to the center $O_{1}^{\prime}$. Similarly, when the floating pinion meshes with gear 2 , the center of floating pinion has a trend to move down to eliminate circumferential backlash $j_{w t 13}$ between floating pinion and gear 3; here, the center $O$ of floating pinion is floated to the center $O_{1}$. Floating range $H 1$ is $\mathrm{O}_{1}-\mathrm{O}_{1}^{\prime}$ and is closely related to the circumferential backlash.

If the equilibrium position of floating pinion is beyond the above-mentioned range, the radial spacing ring will forcibly position the equilibrium position at the boundary of radial spacing ring; here, the radial spacing ring gives a support reaction for floating pinion. The support equilibrium conditions of the floating pinion with the effect of radial spacing ring can be represented as

$$
\begin{array}{r}
\sum\left(\frac{T_{i j}}{r_{b i}} \cdot \cos \chi_{i j}\right)+F_{C x 1}=0 \\
\sum\left(\frac{T_{i j}}{r_{b i}} \cdot \sin \chi_{i j}\right)+F_{C y 1}=0, \\
(i=1, j=2,3) .
\end{array}
$$

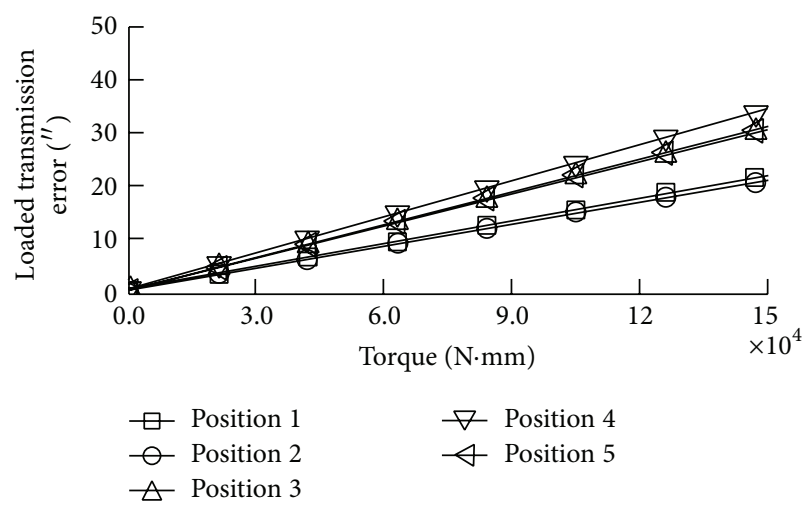

(a) I-stage helical gear pairs

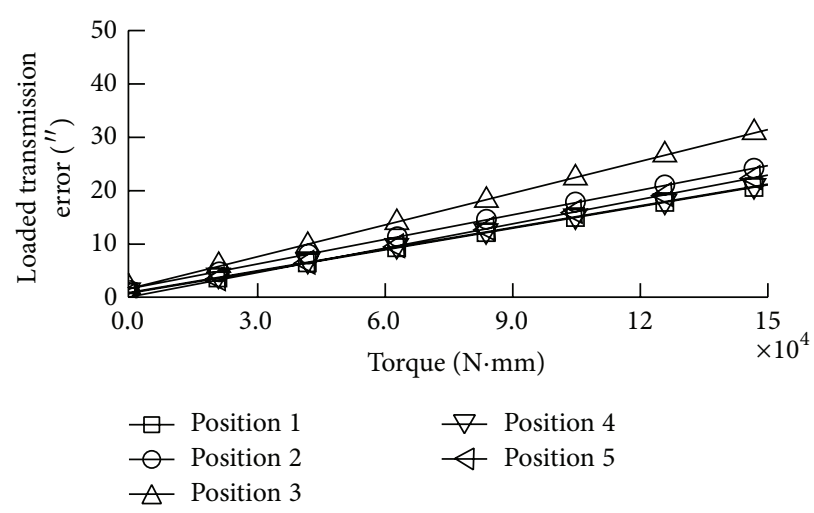

(b) II-stage spur gear pairs

Figure 12: Loaded transmission errors.

TABLE 2: Equivalent supporting rigidity/(N/mm).

\begin{tabular}{lcc}
\hline Gear & $x$-direction & $y$-direction \\
\hline $\mathbf{1}$ & 9236.560 & $\mathbf{1 1 1 4 9 . 0 4 5}$ \\
$\mathbf{2 , 3}$ & 26271.013 & $\mathbf{4 0 6 5 6 . 0 7 7}$ \\
$\mathbf{4 , 5}$ & 22600.646 & $\mathbf{3 8 3 8 1 . 0 1 1}$ \\
\hline $\mathbf{6}$ & $\mathbf{2 1 1 4 3 9 . 0 9 3}$ & $\mathbf{3 2 6 8 0 5 . 0 6 3}$ \\
\hline
\end{tabular}

Here, $F_{C x 1}$ and $F_{C y 1}$ are support reaction of radial spacing ring along $x$-axis and $y$-axis, respectively.

\section{Examples}

In order to have a better comparison between the theoretical and experimental results, all of the parameters reference the reference [4] of the NASA Research Institutions.

Here, gear parameters are shown in Table 1 under the condition of input power $P=373 \mathrm{Kw}$ and input speed $n_{1}=$ $8780 \mathrm{r} / \mathrm{min}$.

Bearing parameters reference the data in Table II of [4]; here, the equivalent supporting rigidity is calculated and shown in Table 2.

The loaded transmission errors of five different engagement positions for three meshing cycles of system are calculated by LTCA and shown in Figure 12. 


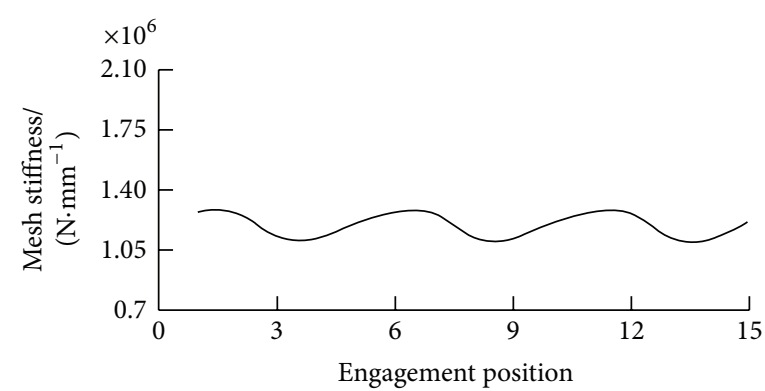

(a) I-stage helical gear pairs

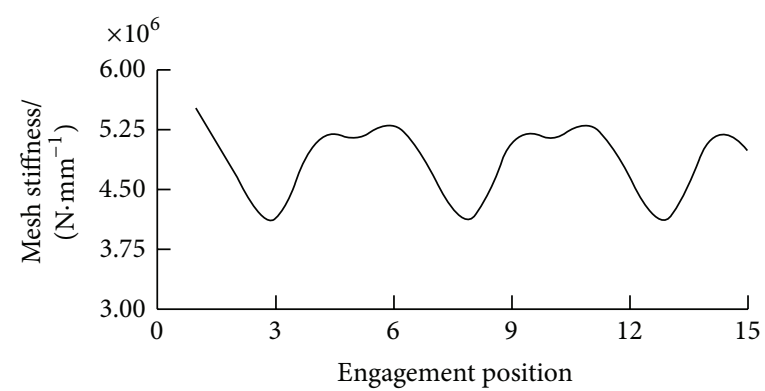

(b) II-stage spur gear pairs

FIGURE 13: Time-varying mesh stiffness.

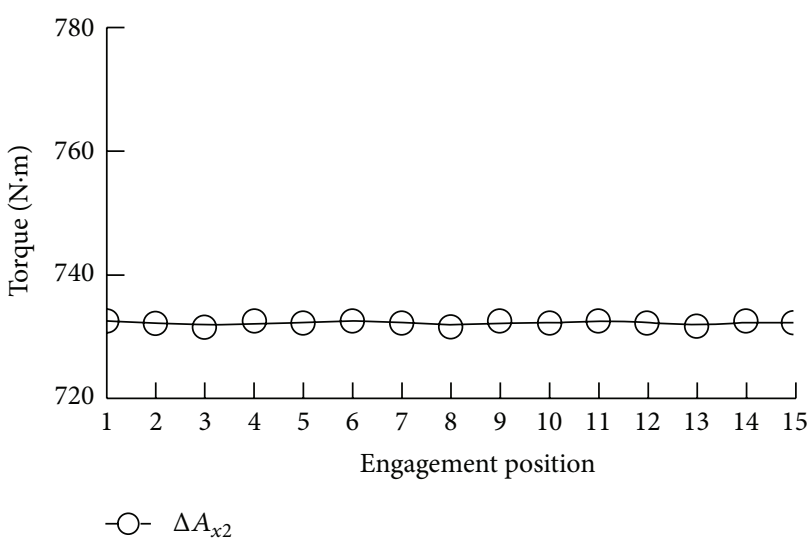

(a) Gear 2 error with $\Delta A_{x 2}$

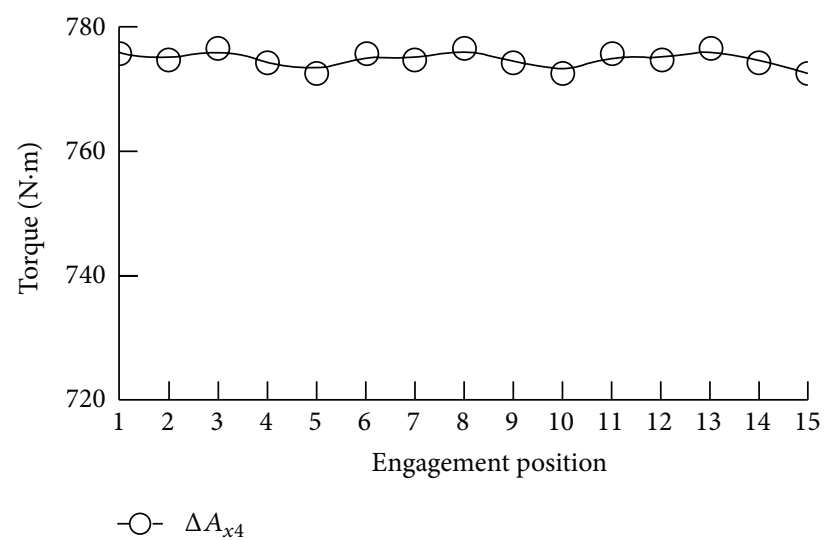

(b) Gear 4 error of $\Delta A_{x 4}$

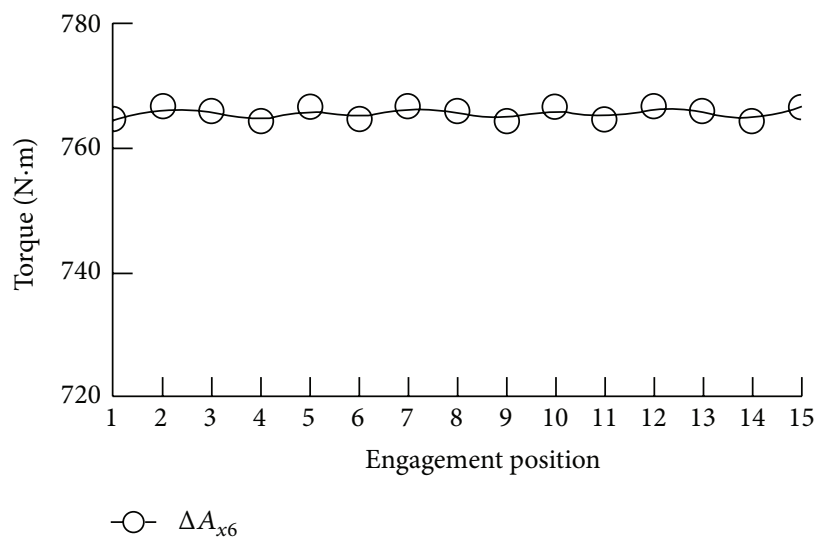

(c) Gear 6 error of $\Delta A_{x 6}$

FIGURE 14: Load-sharing coefficient with installation error.

Then, the time-varying mesh stiffness is calculated and shown in Figure 13.

When the center distance installation errors comprehensively influence the load-sharing characteristics-here, $\Delta A_{x 2}=\Delta A_{x 4}=\Delta A_{x 6}=0.05 \mathrm{~mm}$-the load-sharing coefficient is calculated at 1.0983. When these errors have individual influence on the load-sharing characteristics, the result is shown in Figure 14.

Figure 14 shows that the torque is cyclically fluctuating at each meshing position in different errors of $\Delta A_{x 2}, \Delta A_{x 4}$, and $\Delta A_{x 6}$, which reflect the load distribution at different engagement positions in the tooth surface. Here, the loadsharing coefficient is, respectively, 1.0207, 1.0783, and 1.0641 with the influence of $\Delta A_{x 2}, \Delta A_{x 4}$, and $\Delta A_{x 6}$.

Load-sharing coefficient with a single influence of the center distance installation error is shown in Figure 15. Figure 15 shows the II-stage pinion plays the most important role in the load-sharing coefficient. Thus, during the system installation, the II-stage pinion errors in the load sharing of system should be mainly considered. 


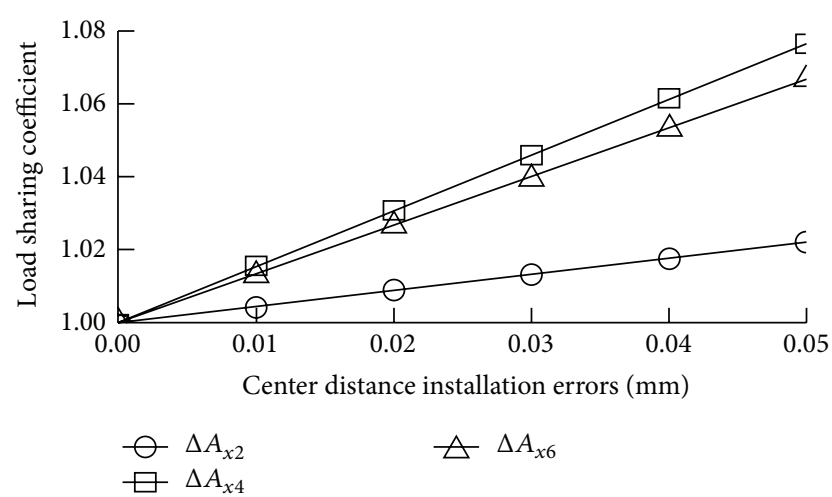

FIGURE 15: Load-sharing coefficient with a single influence of center distance installation errors.

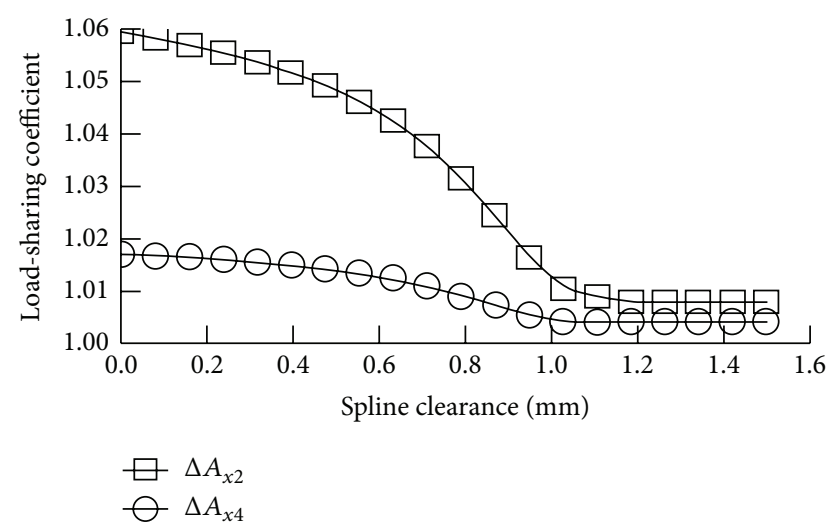

FIGURE 16: The load-sharing coefficient changed with spline clearance.

The influence of the floating pinion based on spline clearance floating is shown in Figure 16.

Here, $\Delta A_{x 2}=0.05 \mathrm{~mm}, \Delta A_{x 4}=0.05 \mathrm{~mm}$, and $\tau=0.1$. Due to the influence of friction, the load-sharing coefficients are 1.0042 and 1.0079 , respectively.

The floating pinion will also be restrained by the radial spacing ring along the radial direction. The effect of the radial spacing ring is shown in Figure 17.

Here, $\Delta A_{y 2}=0.05 \mathrm{~mm} ; \Delta A_{y 4}=0.05 \mathrm{~mm}$. Because the circumferential backlash along the horizontal direction is zero, the floating pinion cannot completely freely float and the center equilibrium position of the floating pinion will be finally fallen on the boundary of the radial spacing ring.

Figure 18 shows the trajectory of center equilibrium position of the floating pinion.

Finally, center equilibrium positions of the floating pinion are $\left(-2.9781 \times 10^{-7}, 0.0183\right)$ and $\left(-4.8338 \times 10^{-6}, 0.0736\right)$, respectively.

\section{Data Analysis and Experiment Results}

The transmission system mentioned in [4] is used for the power transmission device in a helicopter. Reference [4] shows that the clocking is defined by a clocking angle $\beta$, and

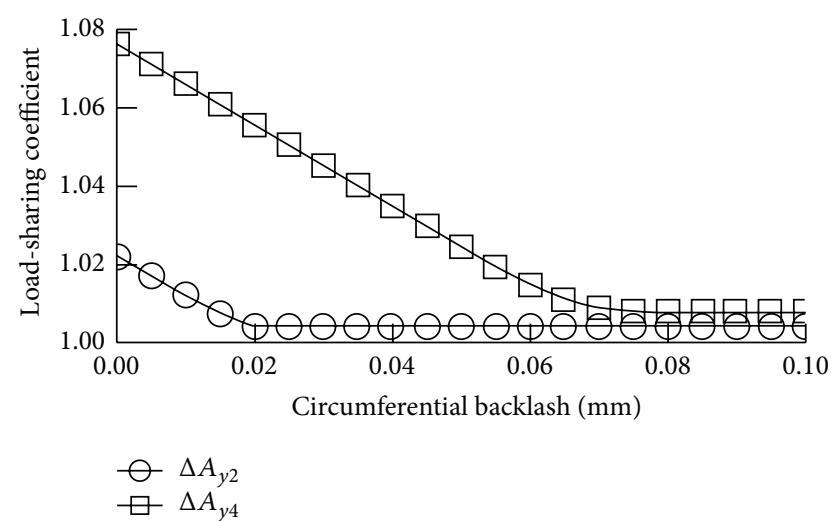

FIGURE 17: The load-sharing coefficient changed with circumferential backlash.

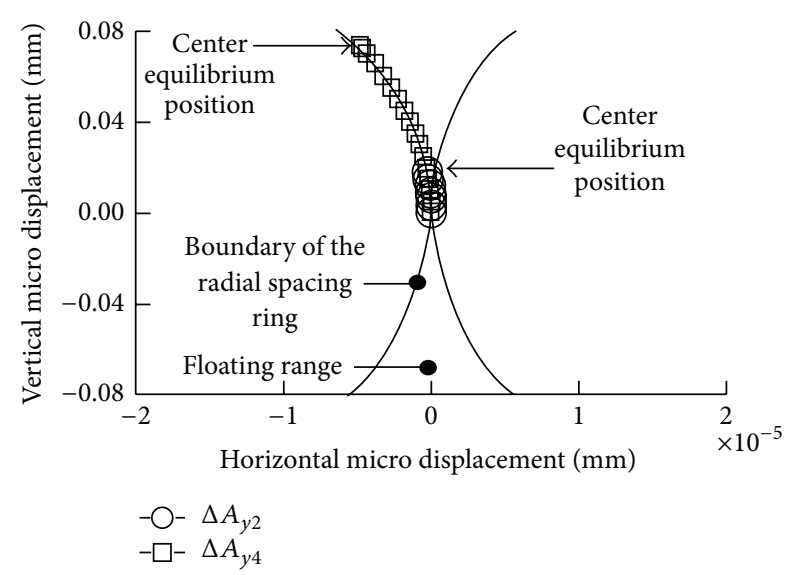

FIGURE 18: Floating trajectory of center equilibrium position.

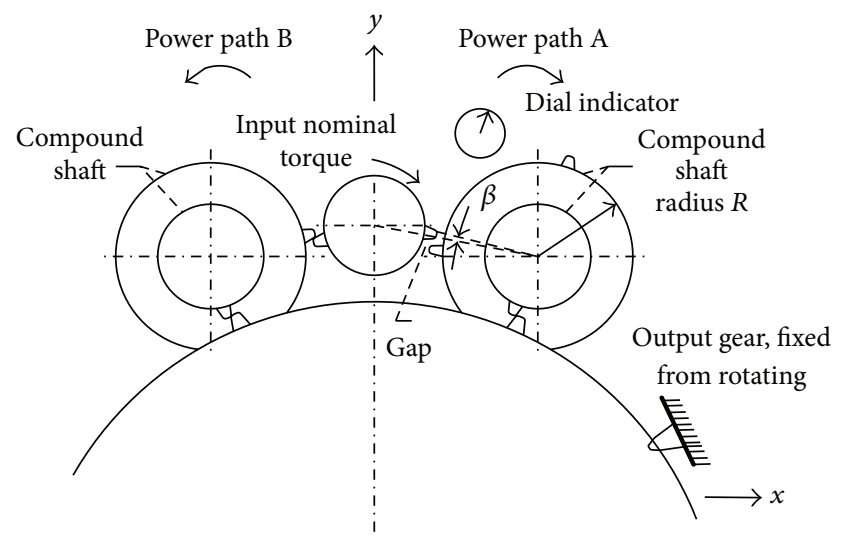

FIGURE 19: Illustration of conceptual experiment to measure clocking angle $\beta$.

the clocking angle is closely related to the load sharing of split path transmission. The clocking angle $\beta$ could be measured by the conceptual experiment depicted in Figure 19. The I-stage gear, torsion shaft, and II-stage gear are collectively called the compound shaft. The two power paths are identified as $\mathrm{A}$ and $\mathrm{B}$, with $\mathrm{A}$ to the right of $\mathrm{B}$. 


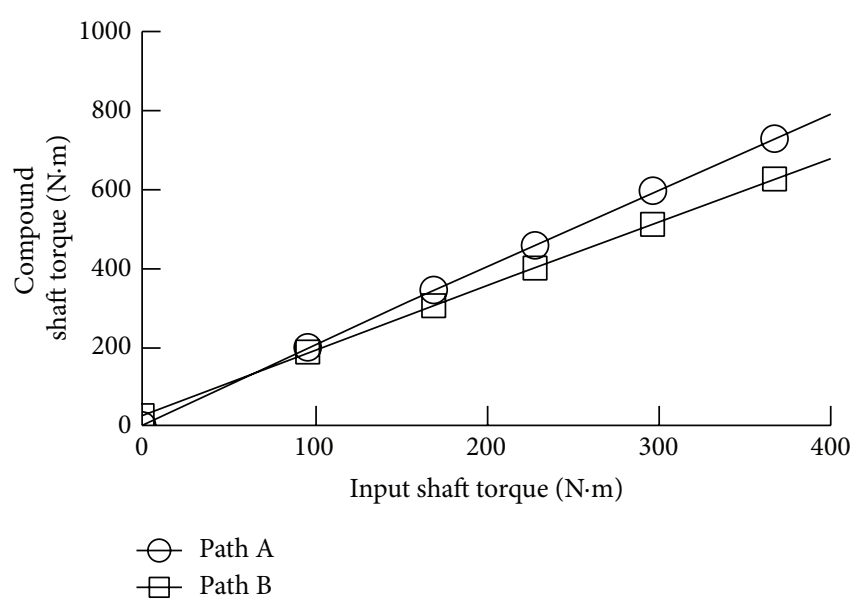

(a)

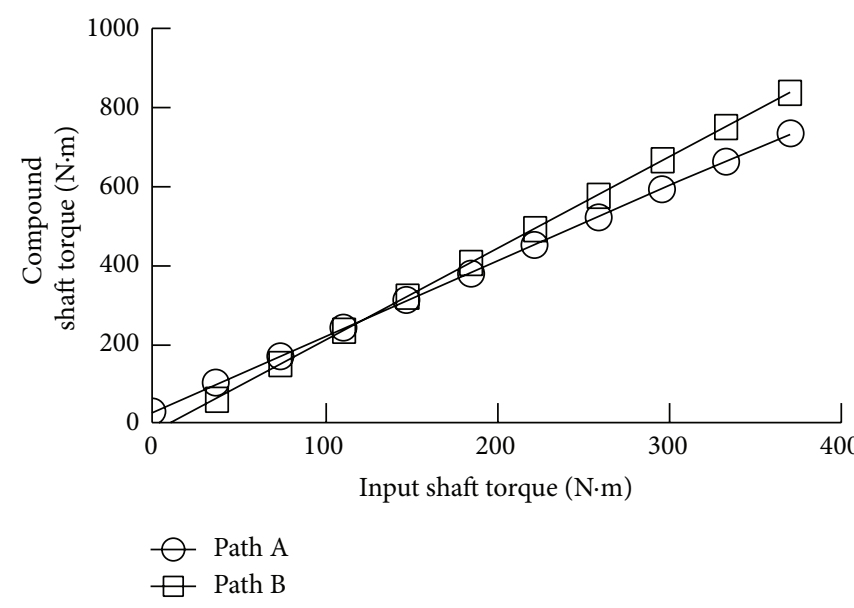

(b)

Figure 20: Typical examples of date and curve fits of compound shaft torques as a function of input shaft torques. (a) Experimental example. (b) Numerical example.

The axial location of each compound shaft depends on the thickness of a shim pack; thus the clocking angle $\beta$ can be easily adjusted by altering the thickness of the shim pack, which effectively screws the helical gear into or out of mesh with its mate.

In order to eliminate the gap, the clocking angles can be adjusted by varying the thicknesses of the shim packs the axially positioned the compound shaft. First, for each shim pack pair tested, find the functions that relate the compound shaft torques to the input shaft torque. Second, relate the shim pack sizes to the clocking angle. Third, use the abovementioned results to find functions that relate the compound shaft torques to the clocking angle for an input shaft torque of $403 \mathrm{~N} \cdot \mathrm{m}$. Finally, use the results of the third point to determine the clocking angles that yield the optimal and the acceptable levels of torque carried by the compound shaft.

Figure 20(a) shows the compound shaft torques change as a function of the input shaft torque; here, the shim pack is set, $3 \mathrm{~mm}$ installed in the system, and the numerical examples are presented in Figure 20(b).

Figure 20(a) for experimental example shows that the torque of path $\mathrm{A}$ is $728.61 \mathrm{~N} \cdot \mathrm{m}$, and the torque of path B is $625.32 \mathrm{~N} \cdot \mathrm{m}$; thus, the power distribution is $53.88 \%$ and the load-sharing coefficient is 1.0776. Figure 20(b) for numerical example shows that the torque of path $\mathrm{A}$ is $838.16 \mathrm{~N} \cdot \mathrm{m}$, and the torque of path B is $733.96 \mathrm{~N} \cdot \mathrm{m}$; thus, the power distribution is $53.31 \%$ and the load-sharing coefficient is 1.0663 .

Therefore, the numerical that is calculated by the aboveproposed method and model is close to the experimental; the correctness of the method and model proposed is verified in this paper.

\section{Conclusions}

After our research and analysis, we can get the following main conclusions:

(1) The deformation compatibility conditions could be able to describe the three-dimension errors of gears in the system, directly representing the mechanical characters of system and accurately describing the meshing process of the gear pairs. It is beneficial to give the power-split transmission system an integral design, analysis, and calculation.

(2) Through the application of LTCA technology, timevarying mesh stiffness can be obtained. This method could improve more the calculating exactness of the load-sharing coefficient. The installation errors accumulatively influence the load-sharing characteristics. The installation errors of the II-stage components should be paid more attention to.

(3) Based on the spline clearance floating and constrained by the radial spacing ring, the floating could improve more the load-sharing characteristics. The quantity of spline clearance should not be excessive. Too much clearance will make the system produce serious vibration and shock.

\section{Conflict of Interests}

The authors declare that there is no conflict of interests regarding the publication of this paper.

\section{Acknowledgments}

This paper received funding from special research projects of Shaanxi Province Education Department, China, Dynamic load-sharing characteristics research on the face gear powersplit drive system based on tooth surface micro modification technology and Xi'an Technology Bureau funded project (cxy1301).

\section{References}

[1] S. J. Tsai, G. L. Hwang, and S. Y. Yeh, "An analytical approach for load sharing analysis of planetary gear drives," in Proceedings 
of the 13th World Congress in Mechanism and Machine Science, Guanajuato, México, June 2011.

[2] A. Singh, A. Kahraman, and H. Ligata, "Internal gear strains and load sharing in planetary transmissions-model and experiments," in Proceedings of the ASME International Design Engineering Technical Conferences \& Computers and Information in Engineering Conference, Las Vegas, Nev, USA, 2007.

[3] S. T. Li, "Effects of machining errors, assembly errors and tooth modifications on loading capacity, load-sharing ratio and transmission error of a pair of spur gears," Mechanism and Machine Theory, vol. 42, no. 6, pp. 698-726, 2007.

[4] T. L. Krantz and I. R. Delgado, "Experimental study of split-path transmission load sharing," NASA TM-107212, NASA Lewis Research Center, 1996.

[5] T. L. Krantz, "A method to analyze and optimize load sharing of split path transmission," NASA TM-107201, NASA Lewis Research Center, 1996.

[6] A. Singh, "Load sharing behavior in epicyclic gears: physical explanation and generalized formulation," Mechanism and Machine Theory, vol. 45, no. 3, pp. 511-530, 2010.

[7] G. White, "Design study of a split-torque helicopter transmission," Proceedings of the Institution of Mechanical Engineers, Part G: Journal of Aerospace Engineering, vol. 212, no. 2, pp. 117-123, 1998.

[8] H. Ligata, A. Kahraman, and A. Singh, "A closed-form planet load sharing formulation for planetary gear sets using a translational analogy," Journal of Mechanical Design, vol. 131, no. 2, pp. $160-167,2009$.

[9] A. Bodas and A. Kahraman, "Influence of carrier and gear manufacturing errors on the static load sharing behavior of planetary gear sets," JSME International Journal, Series C: Mechanical Systems, Machine Elements and Manufacturing, vol. 47, no. 3, pp. 908-915, 2004.

[10] Z. M. Sun, Research on nonlinear dynamics of split-power gear system [Ph.D. thesis], Northwest Polytechnical University of China, 2002, (Chinese).

[11] V. Abousleiman and P. Velex, "A hybrid 3D finite element/lumped parameter model for quasi-static and dynamic analyses of planetary/epicyclic gear sets," Mechanism and Machine Theory, vol. 41, no. 6, pp. 725-748, 2006.

[12] Z. D. Fang, Y. W. Shen, and Z. D. Huang, "The dynamic behaviour of star gearing with three branches," Journal of Aerospace, vol. 17, no. 7, pp. 341-350, 1990.

[13] Q. Y. Yuan, R. P. Zhu, Z. B. Zhu, F. L. Ning, and B. Chen, "Analysis of static load sharing in a 2-stage star gearing system," Mechanical Science and Technology, vol. 23, no. 7, pp. 789-792, 2004 (Chinese).

[14] J.-F. Du, Z.-D. Fang, B.-B. Wang, and H. Dong, "Study on load sharing behavior of planetary gear train based on deformation compatibility," Journal of Aerospace Power, vol. 27, no. 5, pp. 1166-1171, 2012 (Chinese).

[15] H. Dong, Z.-D. Fang, B.-B. Wang, and J.-F. Du, "Load-sharing characteristics of gear train with dual power split based on deflection compatibility," Journal of South China University of Technology, vol. 40, no. 5, pp. 18-23, 2012.

[16] L. F. Litvin and A. Fuentes, Gear Geometry and Applied Theory, Cambridge University Press, Cambridge, UK, 2nd edition, 2004.

[17] J.-G. Gu, Z.-D. Fang, H. Pang, and C. Wang, "Modeling and load analysis of spiral bevel gears power split system," Journal of Aerospace Power, vol. 24, no. 11, pp. 2625-2630, 2009 (Chinese).
[18] Editorial Board of Gear Manual, Gear Manual, China Machine Press, Beijing, China, 2nd edition, 2000, (Chinese).

[19] Z. D. Fang, "Model and approach for loaded tooth contact analysis (LTCA) of gear drives," Mechanical Transmission, vol. 22, no. 2, pp. 1-3, 1998 (Chinese).

[20] F. L. Litvin, J. Lu, D. P. Townsend, and M. Howkins, "Computerized simulation of meshing of conventional helical involute gears and modification of geometry," Mechanism and Machine Theory, vol. 34, no. 1, pp. 123-147, 1999.

[21] Z. D. Fang, "Loaded tooth contact analysis of modified helical gears," Journal of Aerospace Power, vol. 12, no. 3, pp. 251-329, 1997 (Chinese).

[22] S. Li, "Contact stress and root stress analyses of thin-rimmed spur gears with inclined webs," Journal of Mechanical Design, Transactions of the ASME, vol. 134, no. 5, Article ID 051001, 2012. 

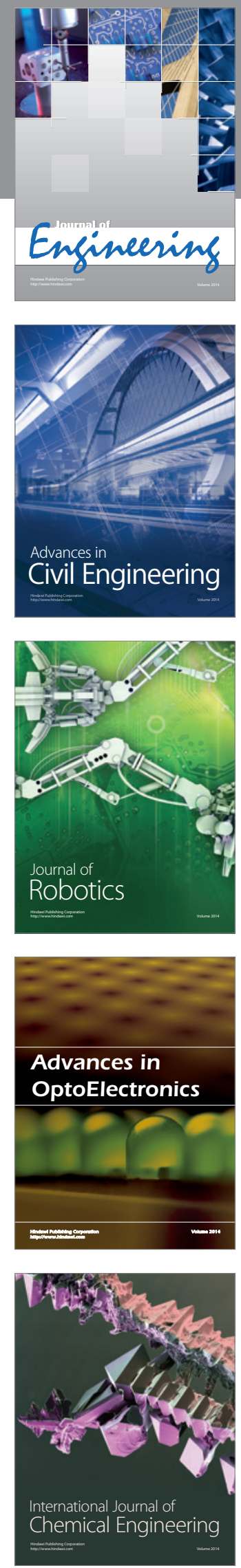

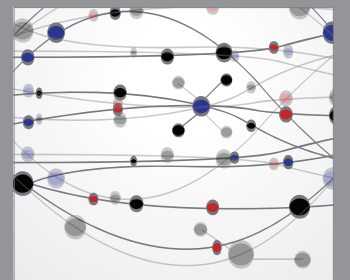

The Scientific World Journal
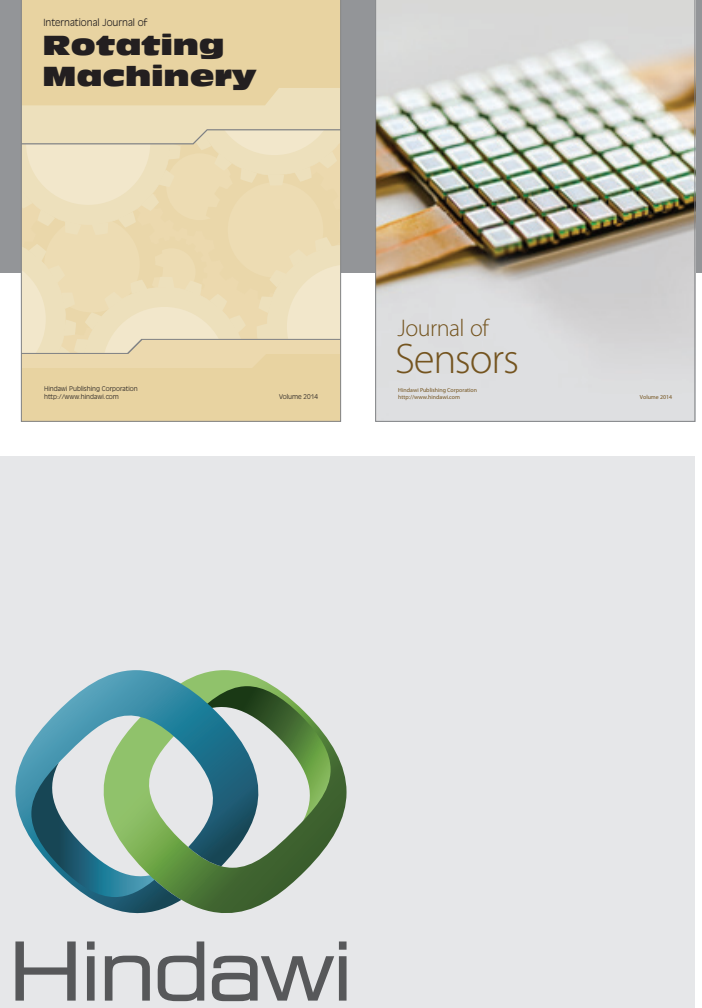

Submit your manuscripts at http://www.hindawi.com
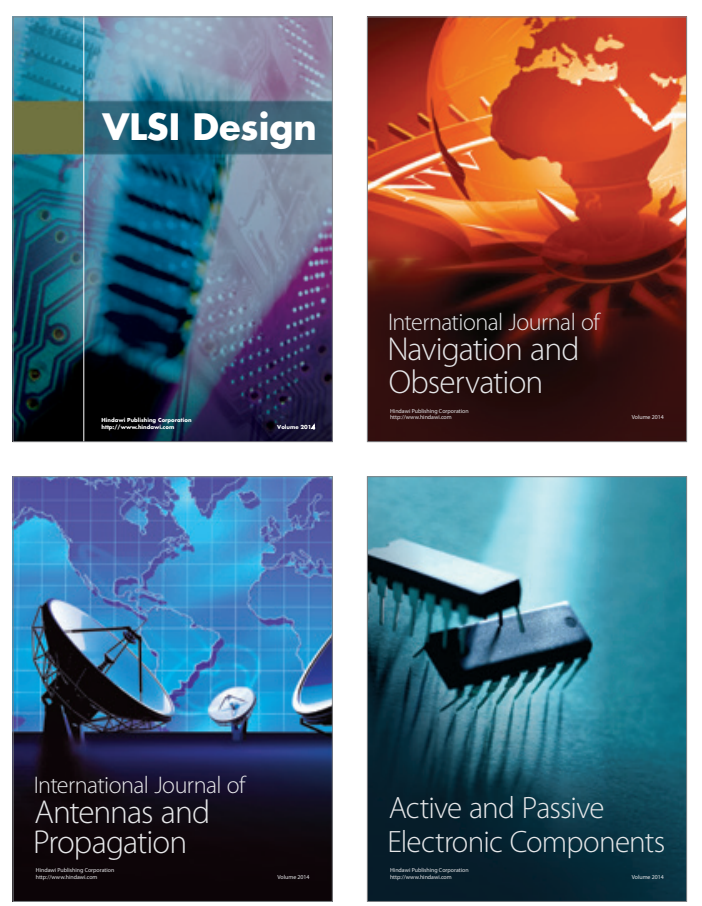
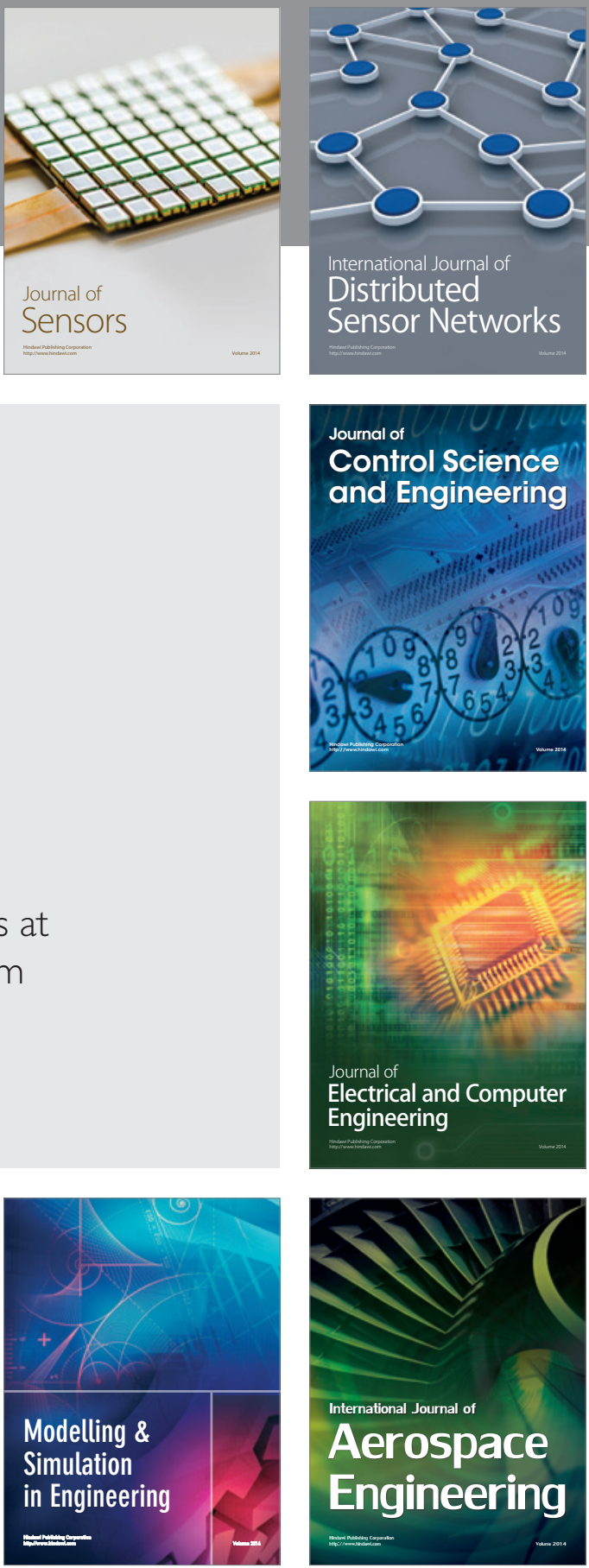

Journal of

Control Science

and Engineering
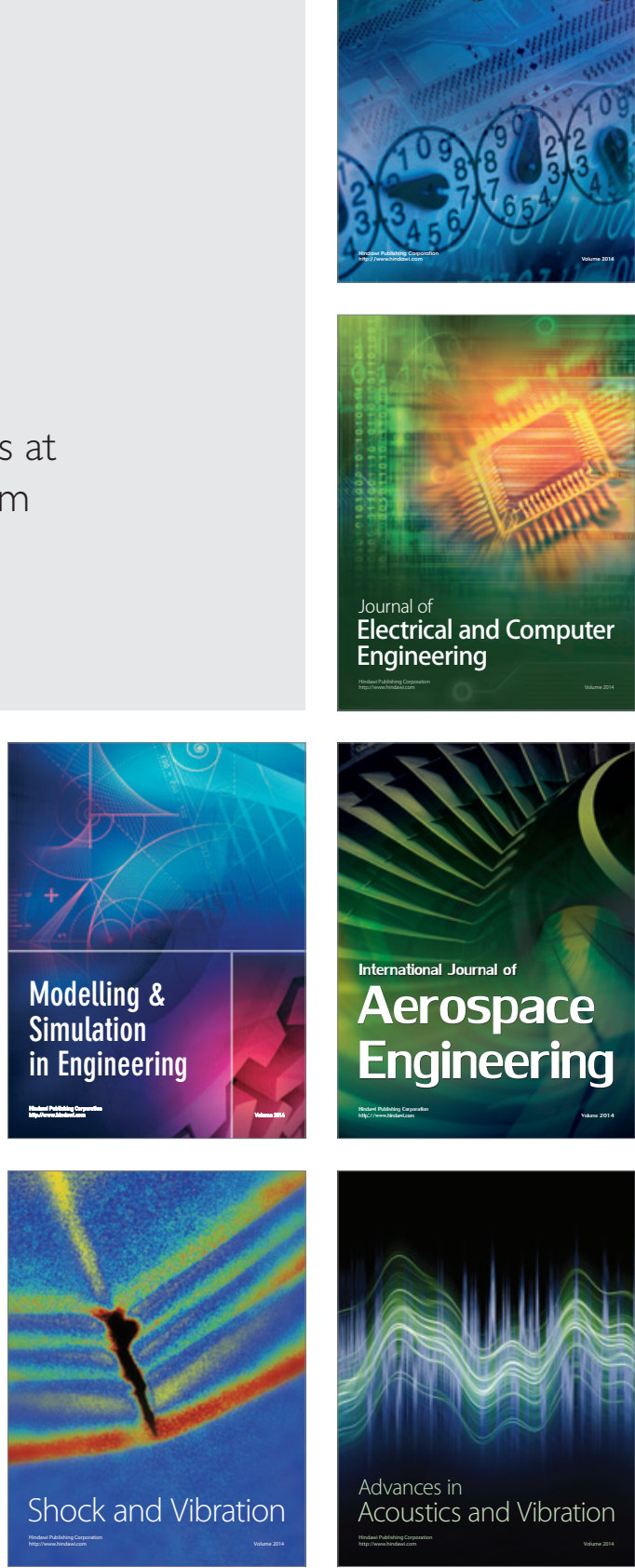